\title{
The association between balance and free- living physical activity in an older community-dwelling adult population: a systematic review and meta-analysis
}

Ilona I. McMullan ${ }^{1,2}$, Suzanne M. McDonough ${ }^{1,2,3}$, Mark A. Tully ${ }^{4^{*}}$ (D, Margaret Cupples ${ }^{5}$, Karen Casson ${ }^{6}$ and Brendan P. Bunting ${ }^{7}$

\begin{abstract}
Background: Poor balance is associated with an increased risk of falling, disability and death in older populations. To better inform policies and help reduce the human and economic cost of falls, this novel review explores the effects of free-living physical activity on balance in older (50 years and over) healthy community-dwelling adults.

Methods: Search methods: CENTRAL, Bone, Joint and Muscle Trauma Group Specialised register and CDSR in the Cochrane Library, MEDLINE, EMBASE, CINAHL, PsychINFO, and AMED were searched from inception to 7th June 2016. Selection criteria: Intervention and observational studies investigating the effects of free-living PA on balance in healthy community-dwelling adults (50 years and older).

Data extraction and analysis: Thirty studies were eligible for inclusion. Data extraction and risk of bias assessment were independently carried out by two review authors. Due to the variety of outcome measures used in studies, balance outcomes from observational studies were pooled as standardised mean differences or mean difference where appropriate and 95\% confidence intervals, and outcomes from RCTs were synthesised using a best evidence approach.

Results: Limited evidence provided by a small number of RCTs, and evidence from observational studies of moderate methodological quality, suggest that free-living PA of between one and 21 years' duration improves measures of balance in older healthy community-dwelling adults. Statistical analysis of observational studies found significant effects in favour of more active groups for neuromuscular measures such as gait speed; functionality using Timed Up and Go, Single Leg Stance, and Activities of Balance Confidence Scale; flexibility using the forward reach test; and strength using the isometric knee extension test and ultrasound. A significant effect was also observed for less active groups on a single sensory measure of balance, the knee joint repositioning test.

Conclusion: There is some evidence that free-living PA is effective in improving balance outcomes in older healthy adults, but future research should include higher quality studies that focus on a consensus of balance measures that are clinically relevant and explore the effects of free-living PA on balance over the longer-term.
\end{abstract}

* Correspondence: m.tully@qub.ac.uk

${ }^{4}$ UKCRC Centre of Excellence for Public Health (NI); Centre for Public Health,

School of Medicine, Dentistry and Biomedical Sciences, Queen's University

Belfast, University Road, Belfast BT7 1NN, Northern Ireland

Full list of author information is available at the end of the article 


\section{Background}

Balance, the ability to stay upright and steady whilst moving or stationary, is a complex skill, that requires the contribution from neuromuscular, cognitive, and sensory body systems [1-3]. Good balance is critical for health and well-being in an ageing population. However, whilst many different biological, environmental, socio-economic, and behavioural risk factors have been identified for poor balance [4-10], the ageing process itself is a key risk factor for poor balance. Through disease or degeneration, ageing results in a decline in systems responsible for balance [11], which increases the risk of falling, injury, loss of independence, illness and even mortality in older adults [8, 12-14]. It is estimated that falls affect between $28-35 \%$ of those aged 65 years or older, and $32-42 \%$ of those aged 70 years or older. Furthermore, the proportion of people aged 60 years or older is growing faster than any other age group and is estimated to reach two billion by 2050, potentially increasing the current human and economic cost of falls by $100 \%$ by $2030[10,15,16]$. Thus, fall prevention is a key challenge.

A body of evidence derived from clinical trials suggests that exercise, a sub-category of physical activity (PA) that is structured, planned, repetitive, and carried out over a relatively short time frame (from one month to a maximum of 12 months with the most frequent being three months) as outlined by Gillespie et al. (2012) [8] (159 studies; 79,193 participants) and Howe et al. (2011) [13] (94 studies; 9, 821 participants), can maintain balance in higher risk older adults such as those living in institutional care, women, or those with chronic illness $(6,13,14]$. It is also proposed that exercise may even reverse the effects of ageing on balance [17]. Exercise recommendations for older adults at higher risk of falls include individually tailored strength and balance exercise programmes such as Tai Chi programmes [10], and guidelines recommend 120-150 min per week of moderately-intensive PA such as aerobic or muscle strengthening exercise [18-20].

However, whilst evidence suggests that exercise can benefit unhealthy older adults at higher risk of falling, the effectiveness of less intensive PA, that is not defined as exercise, in healthy older adults who are at lower risk of falling is less well understood, and guidelines are less explicit in terms of PA type, duration, and intensity for this lower risk population [10, 20]. Also, statistics suggest that exercise levels in older adults are falling [21, 22], and barriers to exercise for them are identified as: fear regarding personal security; lack of time; lack of social support; lack of interest; lack of appropriate facilities; and environmental issues such as the weather [22-24].

Therefore, this review sought to investigate the effect of free-living PA on balance in an older, healthy adult population (aged 50 years or older), with the aim of informing policy and programmes designed to reduce the fall rate and increase PA levels in older adults. Free-living PA is defined as leisure activity based on personal interests and needs (walking, hiking, gardening, swimming, sport, and dance), travel activity (cycling or walking), occupational activity (labouring, gardening, heavy lifting), or planned exercise in the context of daily, family, and community activities (walking programmes, swimming clubs, Tai Chi clubs) [25-27].

\section{Methods}

\section{Data sources, searches, and extraction}

This review followed the Preferred Reporting Items for Systematic Reviews and Meta-Analyses (PRISMA) recommendations and the Cochrane Handbook for Systematic Reviews of Interventions [28, 29]. To strengthen the methodological approach of the review a protocol was developed a priori using the same guidelines and registered on PROSPERO (CRD42016039114).

Eight electronic databases were searched for relevant articles published up until June 2016 and included (the Central Register of Controlled Trials (CENTRAL), the Cochrane Database of Systematic Reviews (CDSR), the Cochrane Bone, Joint and Muscle Trauma Group Specialised, MEDLINE, EMBASE, CINAHL, PsycINFO, and AMED). Search terms were related to population (healthy, $<50 \mathrm{yrs}$ ); intervention (physical activity; activities of daily living, physical mobility, leisure activities, exercise, walking, travel activity, work activity); and outcome of interest (balance, equilibrium, postural control). Details of the MEDLINE search strategy can be found in Additional file 1. In addition, the National Institute for Health Research library [30] and published research on the longitudinal studies of ageing from the English Longitudinal Study of Ageing (ELSA) [31], and the Irish Longitudinal Study on Ageing (TILDA) [32] were screened. Relevant systematic reviews were also manually screened.

Studies were included if they: 1) used an intervention design, or an observational design, 2) included a form of free-living PA, 3) reported a balance outcome measure $[33,34], 4)$ included a comparison group, 5) included a healthy adult population of 50 years or older, 6) were published in English, 7) were peer-reviewed, and 8) had full text. Excluded were studies including unhealthy older adults with conditions that might impact balance [8]; those studies that met the definition of free-living PA but which took place in a researcher environment or a healthcare facility; and those that included only seated PA [19, 35], interventions such as drug therapy or supplements (e.g. vitamin D), or educational or counselling programmes. Details of excluded studies and reasons can be found in Additional file 2.

Using REFWorks (v. 2.0; ProQuest; Mitchigan, US) [36], titles, abstracts and key words were screened independently by two reviewers against the inclusion criteria. The full-text 
of eligible articles were then screened independently by two reviewers and data extracted using a pre-tested data extraction form [29]. Discrepancies were resolved by consensus or by third party adjudication. Table 1 shows characteristics of included studies.

Risk of bias assessment was carried out independently by two reviewers, trialled with a small number of studies to check for understanding, and disagreements were resolved by consensus or third-party adjudication. The Cochrane Collaboration tool was used to assess the quality of included intervention studies [29] by considering their internal validity and risk of bias. The approach considers studies are low risk of bias where risk is low across all domains or most information was from studies at low risk; unclear risk where risk is unclear across all domains or most information was from studies at unclear risk; and high risk of bias where one or more domains were high risk or the proportion of information from studies at high risk was sufficient to affect the interpretation of the results. Observational studies were assessed using a variation of the Newcastle Ottawa Scale (NOS) [37-40], and in the absence of formal threshold scores for rating quality [40] studies were rated as high risk of bias if scored four stars or below, and low risk of bias if scored five stars and above (maximum stars possible was ten).

\section{Data synthesis and analysis}

Data were grouped by study design [41], by PA type [42] and then according to balance outcome measure (direct or indirect) $[13,33]$. Where data were available and appropriate as per the guidelines outlined by the Cochrane Handbook for Systematic Reviews of Interventions [29] a statistical analysis was conducted in RevMan [43] where standardised mean values (95\% confidence intervals (CI)) for balance outcomes between more active and less active groups were compared. Where studies involved multiple intervention groups and more than one group met the inclusion criteria, PA interventions were only compared to minimal intervention controls to avoid double counting [44], in accordance with Ainsworth et al.'s Compendium of Physical Activities' [45]. Additionally, where studies included groups that compared PA levels by gender or age rather than by 'less' or 'more' PA, then where possible, these groups were combined [29]. Due to the statistical and clinical heterogeneity in the balance measures being combined a random-effects model was used to pool the analyses, and heterogeneity was considered large where $p$ $<0.1$, and the $\mathrm{I}^{2}>50 \%$ [29]. Funnel plots that included effect size and standard error were used to examine asymmetry and to assess reporting bias. Post-hoc sensitivity analyses were carried out to assess the possible influence of risk of bias and heterogeneity on the robustness and overall validity of the results where studies were excluded that met high risk of bias criteria (e.g. observational studies with 4 stars or below on NOS; RCTs identified as high risk according to Cochrane's risk of bias tool).

Where insufficient data were available to complete a meta-analysis the data were synthesised qualitatively using a best evidence synthesis advocated by van Tulder et al. [46] where evidence is considered 1) strong; consistent findings in multiple RCTs assessed as having low risk of bias; 2) moderate; consistent findings in one RCT assessed as having low risk of bias, and one or more RCTs assessed as having high risk of bias, or by generally consistent findings in multiple RCTs assessed as having high risk of bias; 3) limited or conflicting evidence; only one RCT (assessed as having either a low or high risk of bias), or inconsistent findings in multiple RCTs; and 4) no available evidence; no published RCTs that have assessed interventional effect.

\section{Results}

A total of 2364 articles were identified by the search strategy. From the title, abstract, and keywords, two reviewers independently identified 82 relevant studies for full text review. From the full text review, 52 were excluded resulting in 30 papers being reviewed $(n=1547$ participants). The process, including reasons for exclusions, is shown in Fig. 1 [28].

\section{Observational studies}

\section{Design, sample size, and location}

Twenty-six studies were observational (one prospective cohort [47], and 25 cross sectional). Sample size ranged from 23 [48] to 170 [47] with an average of 54 participants, but only one study carried out a sample size calculation [49].

Fourteen studies did not specify study location [50-63]; one study was carried out in Japan [47]; four in China [48, 64-66]; two in Taiwan $[67,68]$; one in the UK [69]; two in US [49, 70]; one in Brazil [71]; and one in France [72].

\section{Participants}

Participants across all studies were defined as healthy and resided in the community (62\% women; mean age $=$ 66.93 years). Age groups included were: $50-60$ years in two studies [52, 66]; 61-70 years in 15 studies [48-51, 53, 59-64, 67-69, 71] and 71 years or over in eight studies $[47,54-56,58,65,70,72]$.

There was a lack of demographics in included studies where only one study reported marital status [57], and one study reported ethnicity and education [49].

\section{Physical activity}

All PA interventions were land based except for two studies that included mixed PA with a component of swimming $[51,72]$. Sixteen studies included 3D PA (e.g. dance and tai chi) [42] ( $n=842$ participants), and ten included 'General' PA (e.g. walking, cycling) [42] ( $n=505$ participants). Only 


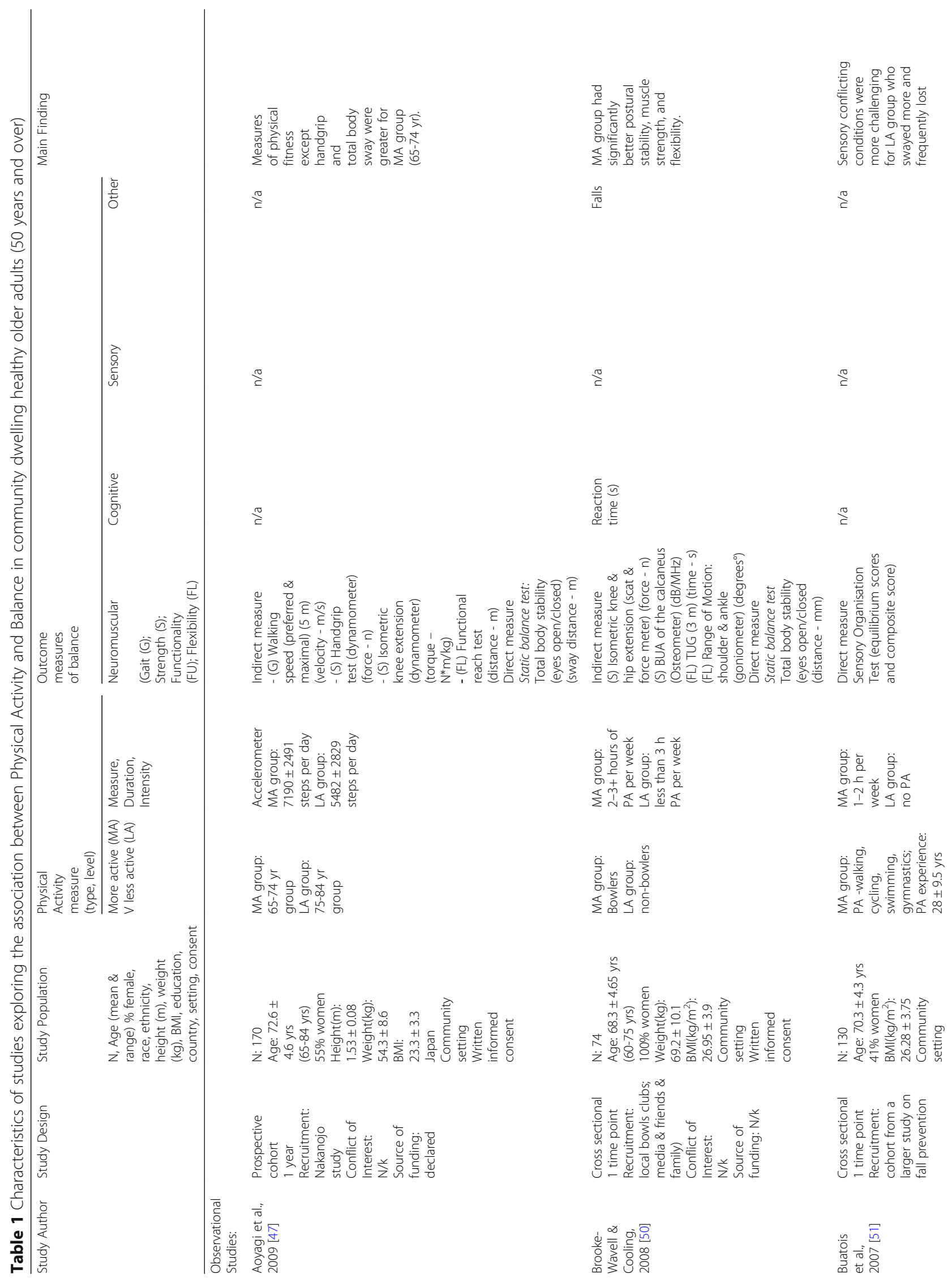




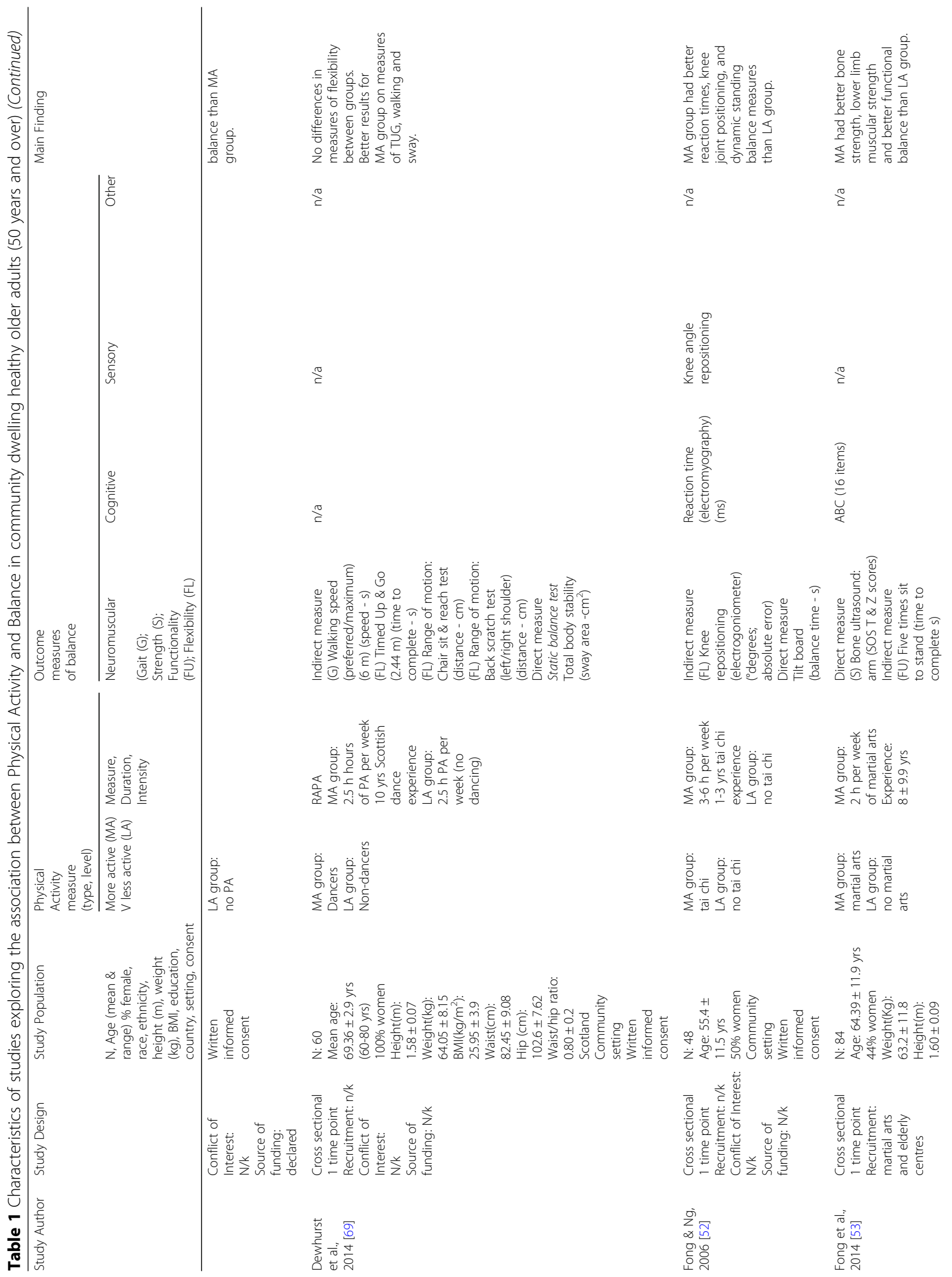




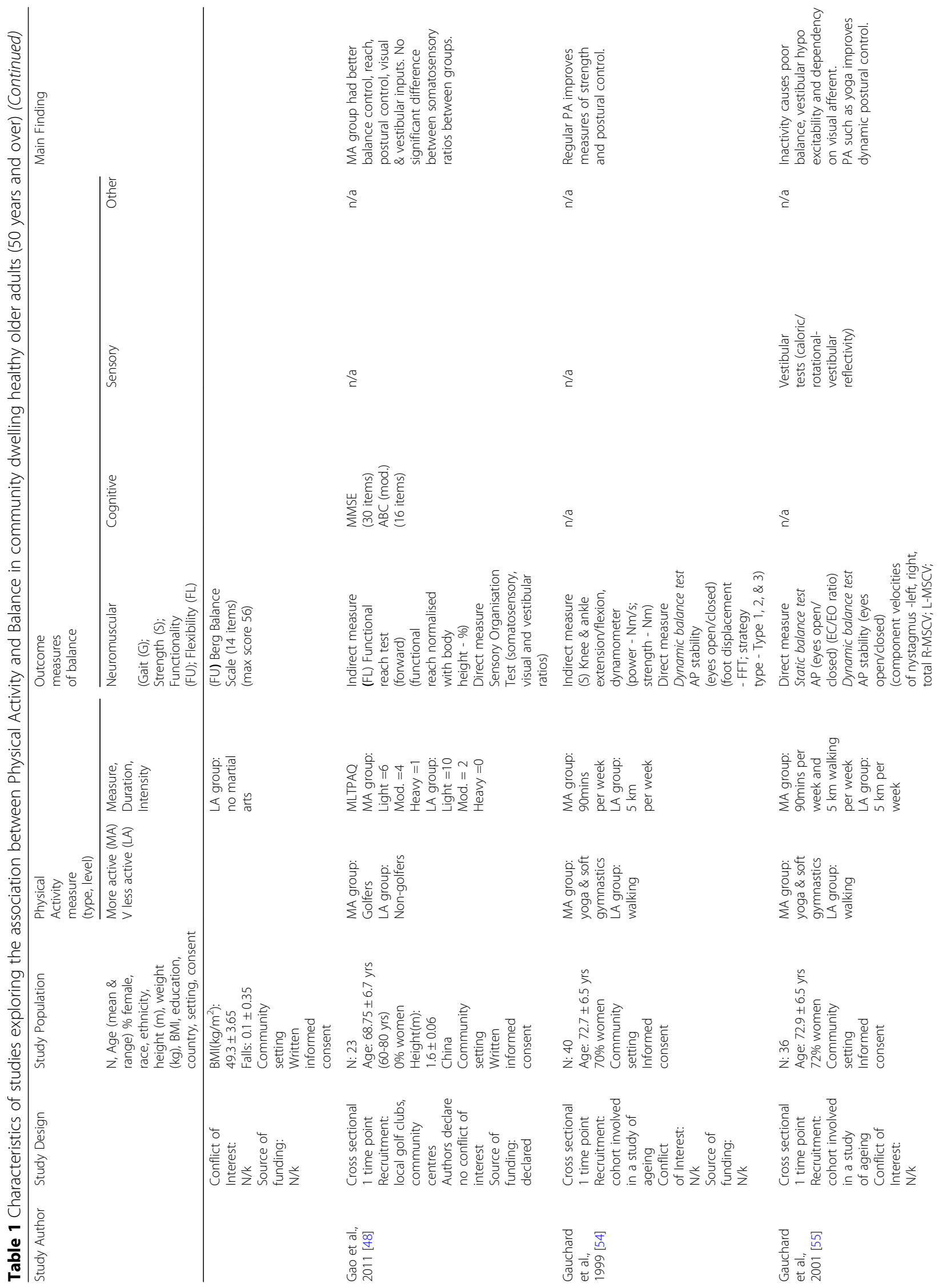




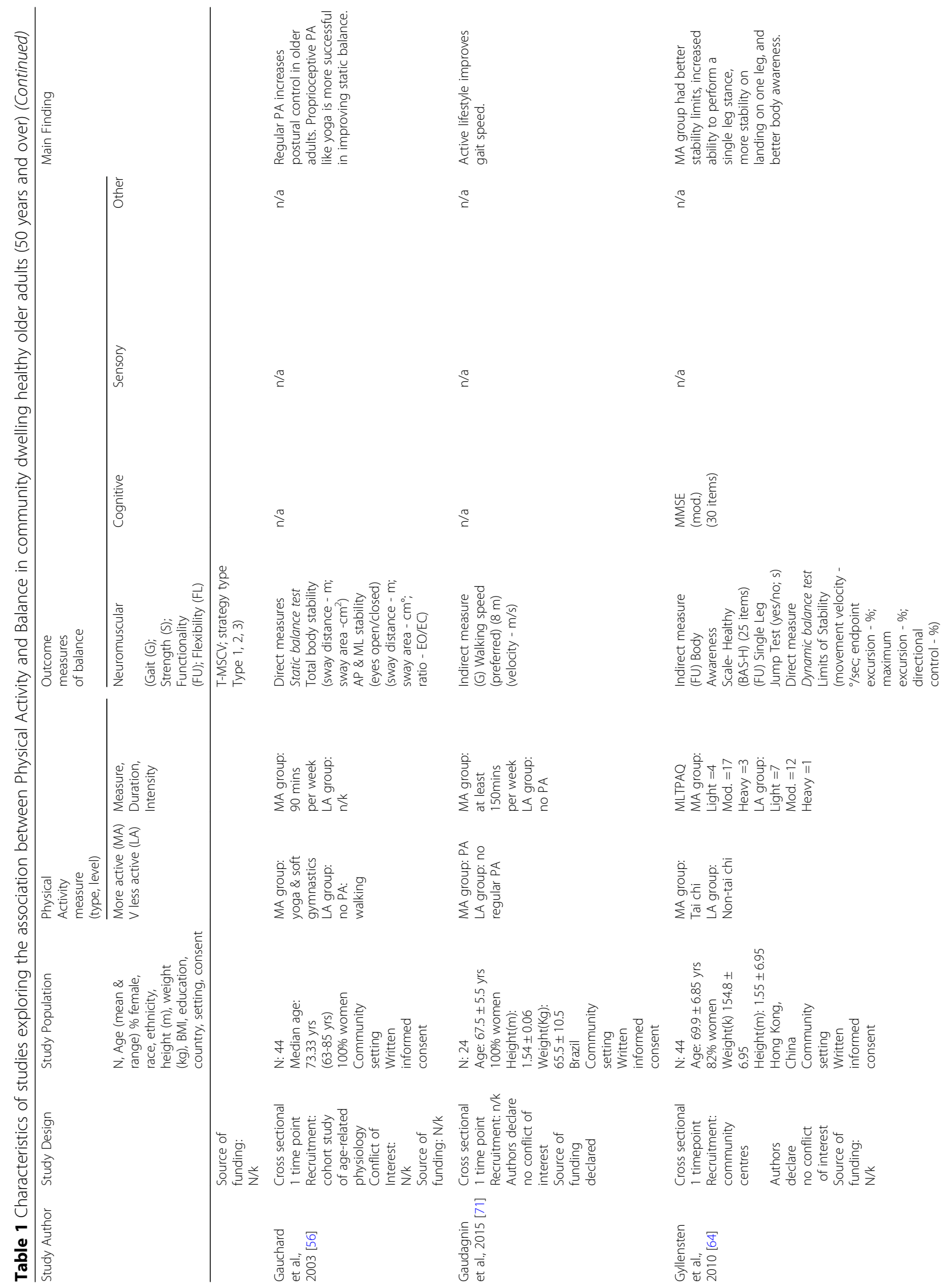




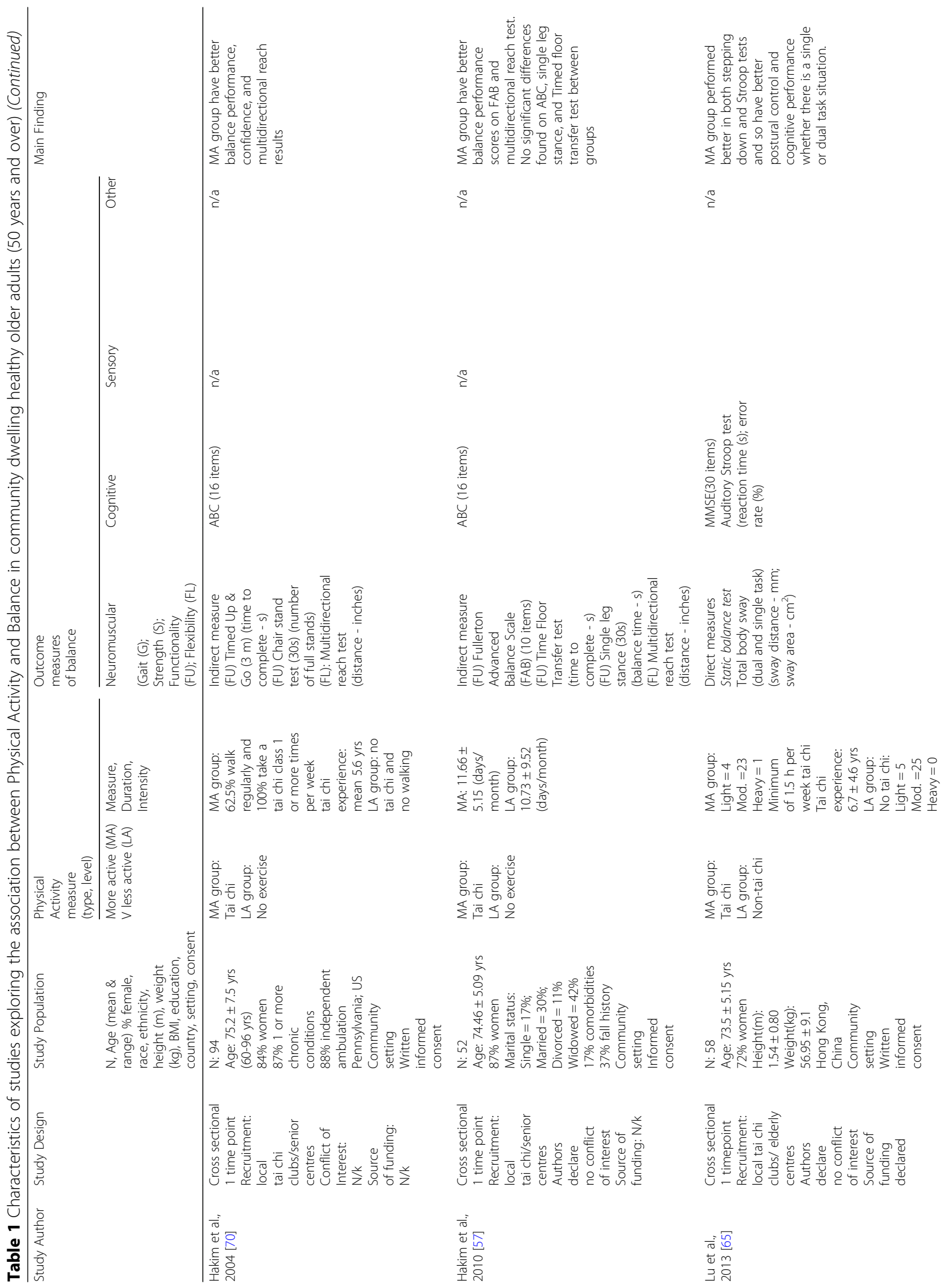




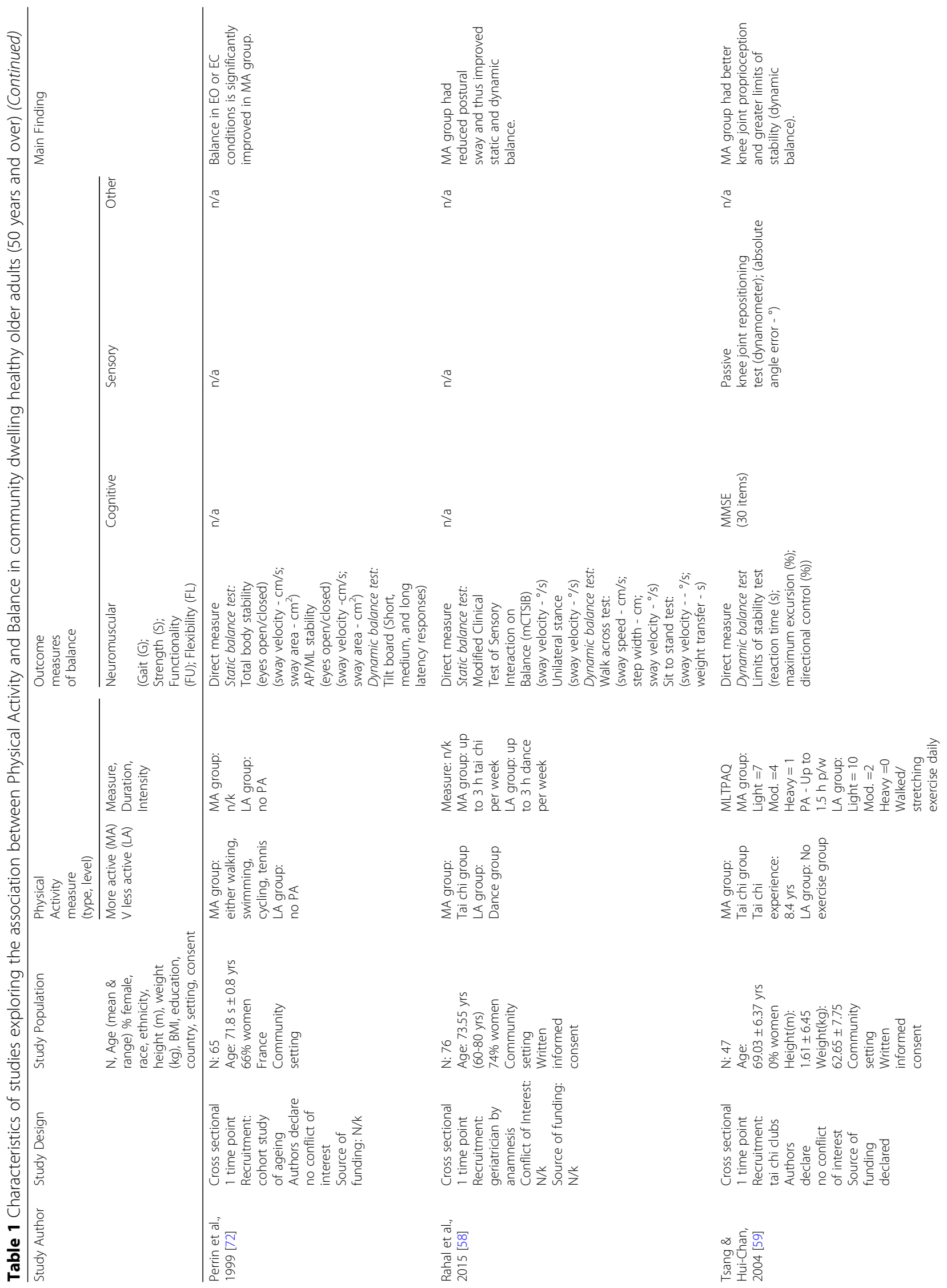




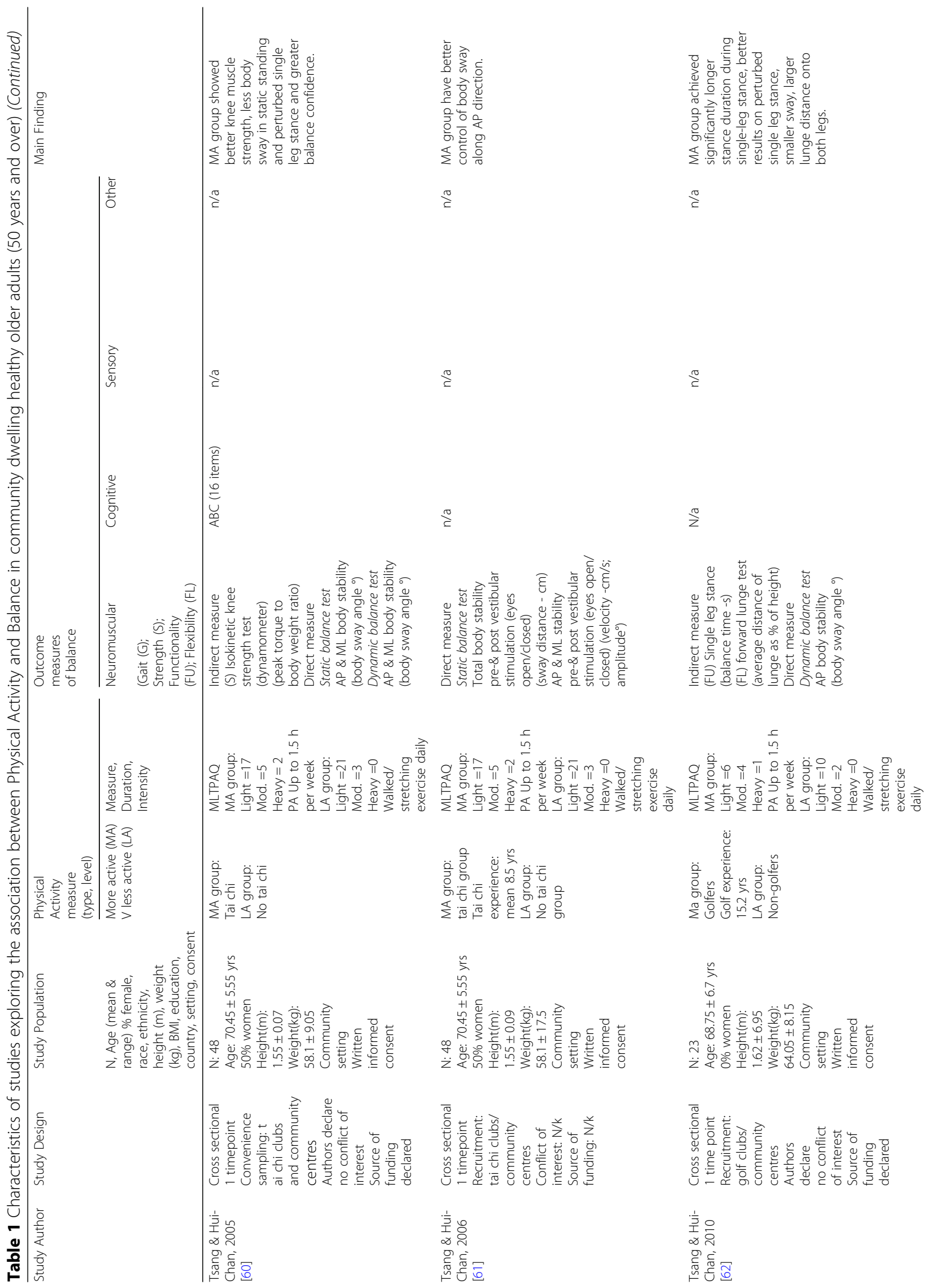




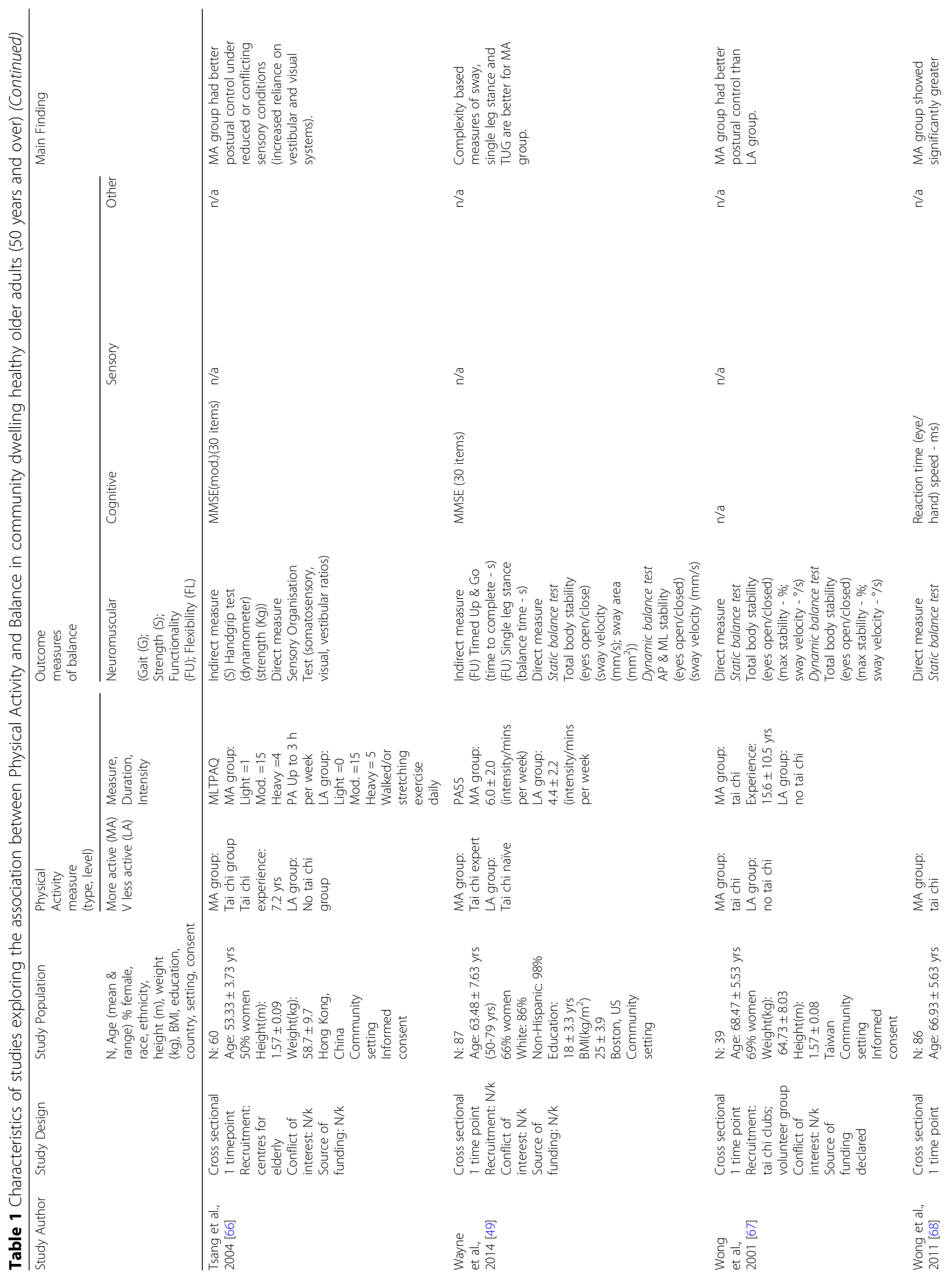




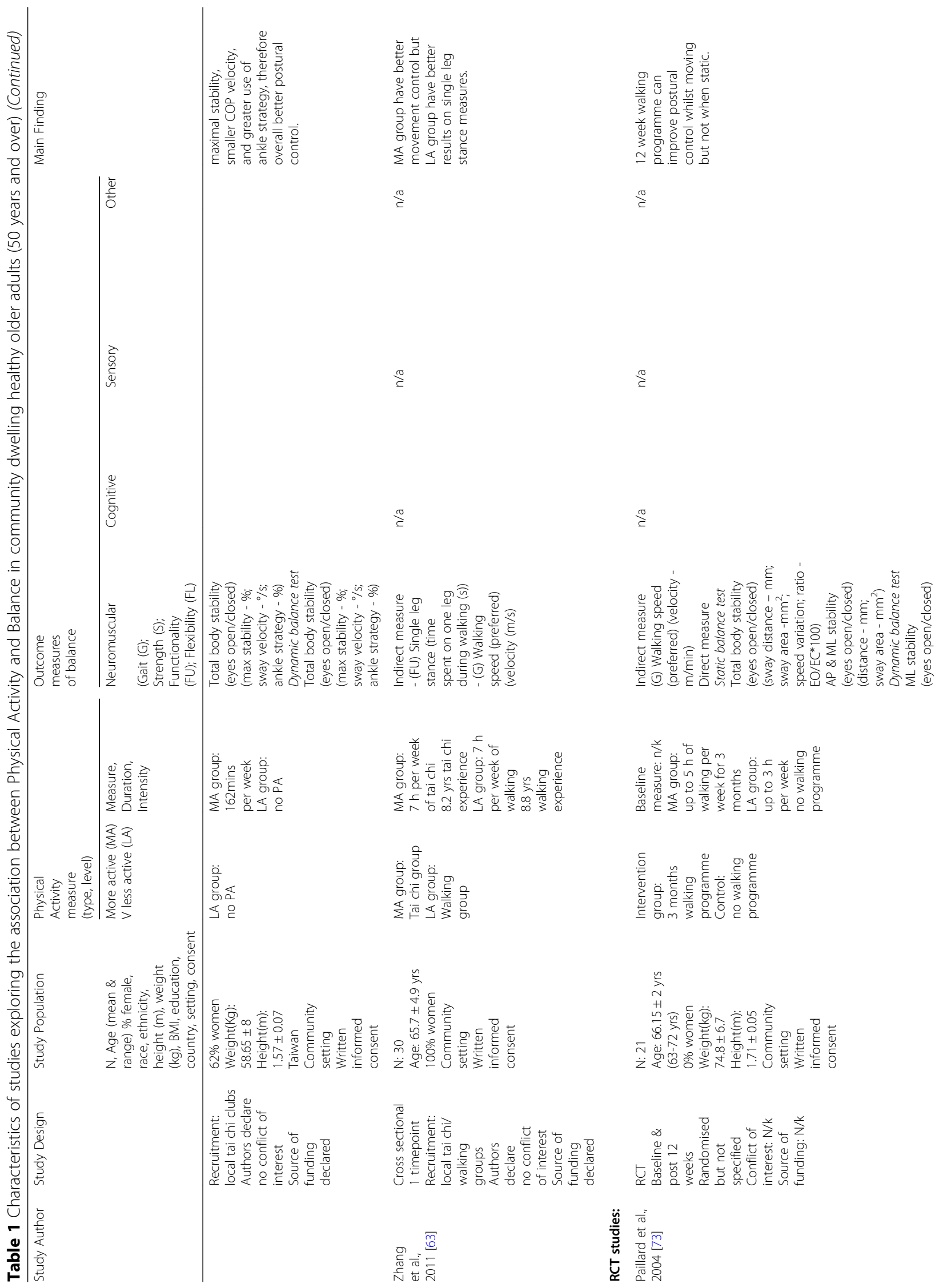




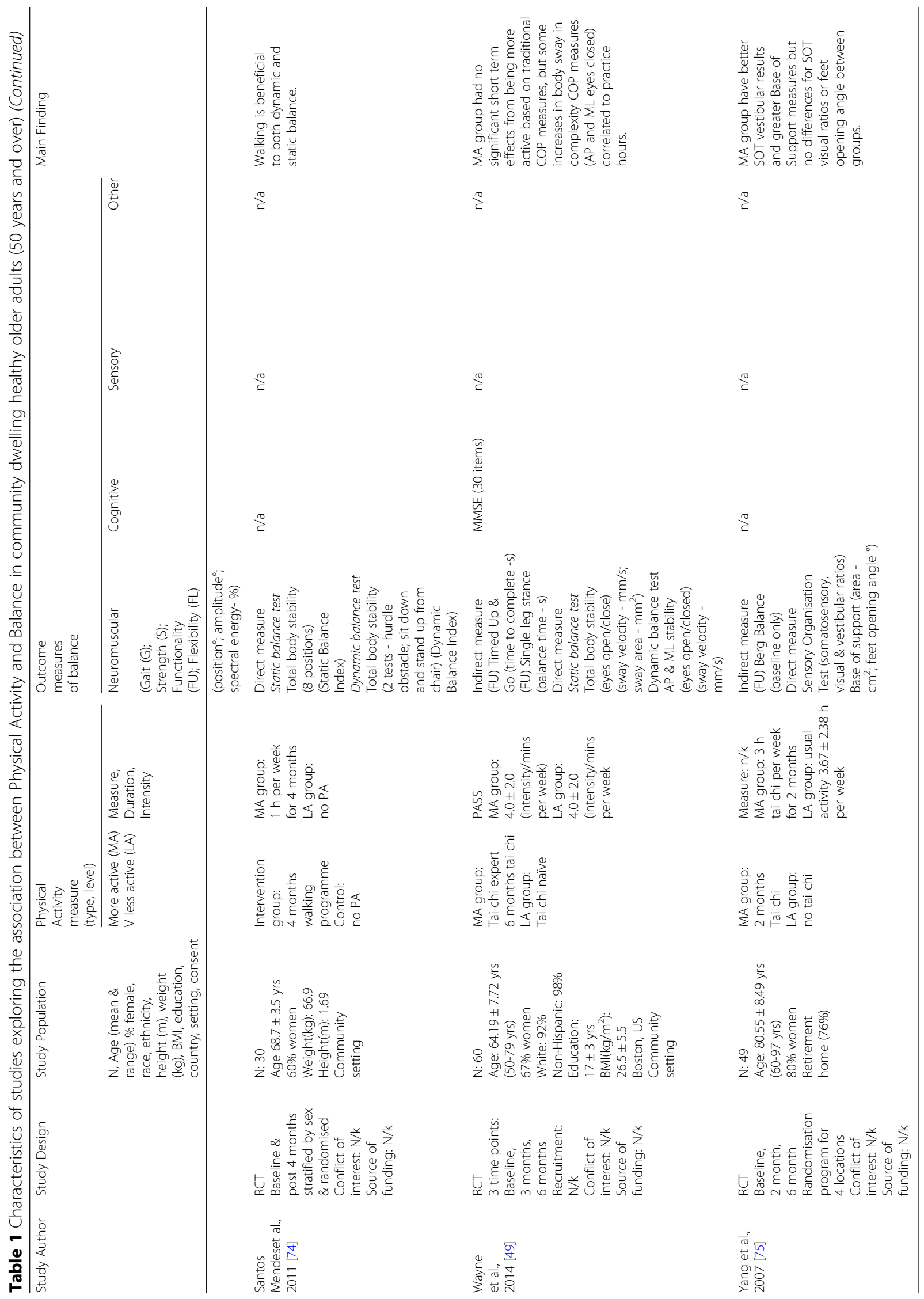




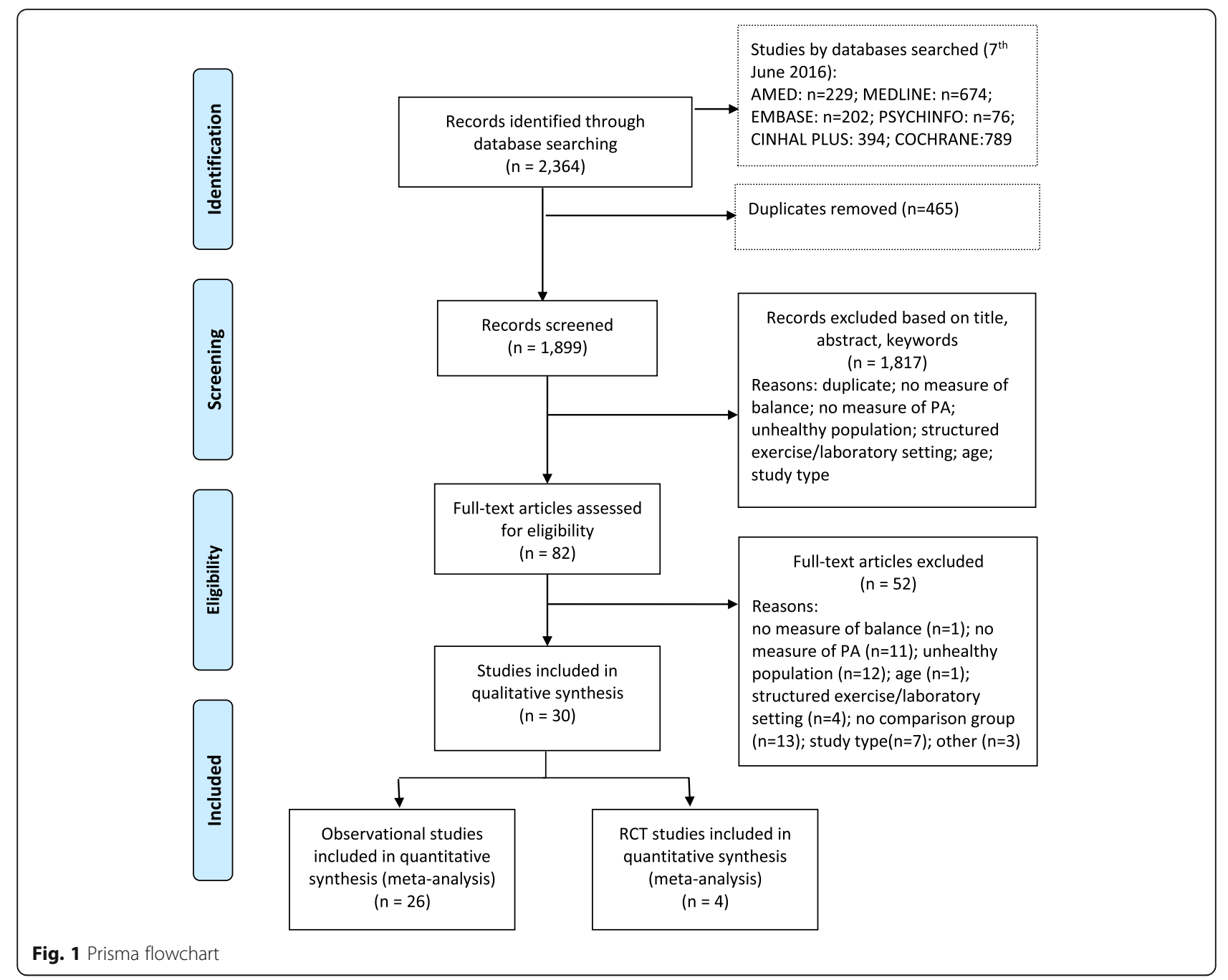

one study used an objective measure of PA, an accelerometer, measuring steps per day [47], whilst nine used a variety of validated questionnaire based measures (e.g. Rapid Assessment of Physical Activity (RAPA), Physical Activity Status Score (PASS), Minnesota Leisure Time Physical Activity Questionnaire (MLTPAQ) [48, 49, 59-62, 64, 66, 69], and 16 did not specify the tool used [50-58, 63, 65, $67,68,70-72]$.

All studies included a less active group and a more active group and long-term practice of PA ranging from one to 21 years and over, with two identifying one to five years [47, 52]; eight identifying six to ten years [53, 59, 61, $63,65,66,69,70]$; one identifying $11-15$ years [62]; one identifying $16-20$ years [67]; and one identifying 21 years and over [51]. Thirteen studies did not specify PA duration [48-50, 54-58, 60, 64, 68, 71, 72].

\section{Balance}

Overall, studies included multiple balance measures, except for three that included only one measure [51, 59, 71].
Sixteen studies included indirect measures relating to the neuromuscular system ( $n=961$ participants) [47-50, 5254, 57, 60, 62-64, 66, 69-71]. Thirteen studies included indirect measures of cognitive function $(n=805$ participants) $[48-50,52,53,57,59,60,64-66,68,70]$. Only three studies included any sensory system measures $(n=131$ participants) $[52,55,59]$ and these included proprioception measures. Only one study [50] reported fall rate. Some studies met our inclusion criteria but were excluded from the analyses due to inadequate data and the authors provided no further information on request $(n=159$ participants) [56, 58, 67]. Results were estimated from graphical information in seven studies ( $n=429$ participants) $[51,52,54,55,68,71,72]$.

Secondary outcome measures Three studies used the Sensory Organisational Test (SOT) $[48,51,66](n=139$ participants). Force platforms for the measurement of sway for static or dynamic balance were used in 17 studies ( $n=1028$ participants) $[47-50,55,56,58-62,64,65,67-$ 
$69,72]$. The ability to maintain balance whilst standing on a tilt board was measured in one study $(n=48$ participants) [52].

\section{Quality}

Table 2 presents a summary table of the risk of bias of included observational studies and shows that in general studies were of moderate quality ( $n=14$ studies). All studies rated poor in terms of comparability of participants; the majority ( $n=14$ studies) failed to provide details relating to selection process, but the measures of balance included in studies were validated and stated in the main objective.

\section{Effects of more PA versus less $P A$}

Primary outcomes (indirect measures of balance). Initial analyses included 16 variables (20 studies; $n=1053$ participants) (Table 3). Sensitivity analysis removed five variables (which are excluded from Table 3) due to their high risk of bias (maximal walking speed, functional reach in back, left and right directions, and range of motion), resulting in only 11 variables (13 studies; 733 participants).

Sensitivity analyses showed significant differences between more and less active groups for two variables (preferred walking speed and SLS), which were not identified in initial analyses, but otherwise did not alter findings (Table 3).

Neuromuscular measures Table 3 shows that more active groups achieved faster gait speed (SMD $0.66 \mathrm{~m} / \mathrm{s}$ ); better results for two measures of strength using ultra sound tests (SMD 0.57) and isometric knee extension tests (SMD 0.64); better results for three measures of functionality with longer time on SLS test (SMD 1.17s), higher scores on $\mathrm{ABC}$ (SMD 1.47), and faster time taken to complete the TUG test (SMD -0.70s); and better

Table 2 Newcastle-Ottawa Scale risk of bias assessment of observational studies

\begin{tabular}{|c|c|c|c|c|}
\hline Study & $\begin{array}{l}\text { Selection } \\
\text { (max. } 5 \text { stars) }\end{array}$ & $\begin{array}{l}\text { Comparability } \\
\text { (max. } 2 \text { stars) }\end{array}$ & $\begin{array}{l}\text { Outcome } \\
\text { (max. } 3 \text { stars) }\end{array}$ & $\begin{array}{l}\text { Total } \\
\text { (max. } 10 \text { stars) }\end{array}$ \\
\hline Aoyagi et al., 2009 [47] & **** & * & $* * *$ & 7 \\
\hline Brooke-Wavell \& Cooling, 2008 [50] & * & * & $* * *$ & 5 \\
\hline Buatois et al., 2007 [51] & * & $*$ & $* * *$ & 5 \\
\hline Dewhurst et al., 2014 [69] & $* *$ & & $* *$ & 4 \\
\hline Fong \& Ng, 2006 [52] & * & * & $* * *$ & 5 \\
\hline Fong et al.,2014 [53] & * & * & $* * *$ & 5 \\
\hline Gao et al., 2011[48] & $* * *$ & * & $* * *$ & 7 \\
\hline Gauchard et al., 1999 [54] & * & & $* * *$ & 4 \\
\hline Gauchard et al., 2001[55] & * & & $* * *$ & 4 \\
\hline Gauchard et al., 2003[56] & * & & $* *$ & 3 \\
\hline Gaudagnin et al., 2015 & * & & $* * *$ & 4 \\
\hline Gyllensten et al., 2010 [64] & $* * *$ & * & $* * *$ & 7 \\
\hline Hakim et al., 2004[70] & * & & $* * *$ & 4 \\
\hline Hakim et al., 2010 [57] & * & & $* * *$ & 4 \\
\hline Lu et al., 2013[65] & $*$ & * & $* * *$ & 5 \\
\hline Perrin et al., 1999[72] & * & & $* * *$ & 4 \\
\hline Rahal et al., 2015[58] & & & $* *$ & 2 \\
\hline Tsang \& Hui-Chan, 2004 [59] & $* * *$ & & $* * *$ & 6 \\
\hline Tsang \& Hui-Chan, 2005 [60] & $* * *$ & * & $* * *$ & 7 \\
\hline Tsang et al., 2004 [66] & $* * *$ & & $* * *$ & 6 \\
\hline Tsang \& Hui-Chan, 2006 [61] & $* * *$ & * & $* * *$ & 7 \\
\hline Tsang \& Hui-Chan, 2010 [62] & $* * *$ & * & $* * *$ & 7 \\
\hline Wayne et al., 2014 [49] & $* * *$ & * & $* * *$ & 7 \\
\hline Wong et al., 2001 [67] & * & * & $* * *$ & 4 \\
\hline Wong et al., 2011 [68] & & * & $* * *$ & 4 \\
\hline Zhang et al., 2011 [63] & & * & $* * *$ & 4 \\
\hline
\end{tabular}


Table 3 Primary outcomes - more active versus less active groups (Indirect measures of balance)

\begin{tabular}{|c|c|c|c|c|}
\hline Comparison or subgroup & No. of studies & $\mathrm{N}$ & Effect size $(95 \% \mathrm{Cl})$ & Heterogeneity \\
\hline \multicolumn{5}{|l|}{ Neuromuscular measure of gait } \\
\hline *1 Preferred walking speed (m/s). & 4 & 284 & $0.24(-0.69,1.17)$ & $91 \%$ \\
\hline Preferred walking speed $(\mathrm{m} / \mathrm{s})$. & 2 & 194 & $0.66(0.26,1.06)$ & $20 \%$ \\
\hline \multicolumn{5}{|l|}{ Neuromuscular measures of strength } \\
\hline *2 Handgrip $(\mathrm{Kg}) .++$ & 2 & 210 & $1.73(-1.20,4.66)$ & $23 \%$ \\
\hline *3 Isometric knee extension. & 4 & 320 & $0.63(0.40,0.87)$ & $35 \%$ \\
\hline 3.1 Isometric knee extension. & 3 & 292 & $0.64(0.35,0.94)$ & $25 \%$ \\
\hline *4 Ultrasound. & 2 & 158 & $0.57(0.25,0.89)$ & $0 \%$ \\
\hline \multicolumn{5}{|l|}{ Neuromuscular measures of functionality } \\
\hline *5 Timed Up \& Go. (s) Low value indicates better balance. & 4 & 286 & $-0.76(-1.01,-0.51)$ & $0 \%$ \\
\hline 5.1 Timed Up \& Go. (s) Low value indicates better balance. & 2 & 161 & $-0.70(-1.03,-0.37)$ & $0 \%$ \\
\hline *6 Single Leg Stance. (s) & 4 & 181 & $-0.25(-1.86,1.37)$ & $95 \%$ \\
\hline 6.1 Single Leg Stance. (s) & 2 & 110 & $1.17(0.74,1.60)$ & $0 \%$ \\
\hline *7 Activities of Balance Confidence. & 4 & 220 & $1.33(0.73,1.94)$ & $74 \%$ \\
\hline 7.1 Activities of Balance Confidence. & 3 & 155 & $1.47(0.70,2.25)$ & $70 \%$ \\
\hline \multicolumn{5}{|l|}{ Neuromuscular measures of flexibility } \\
\hline *8 Functional reach (forward) (m). & 4 & 304 & $1.18(0.61,1.75)$ & $74 \%$ \\
\hline 8.1 Functional reach (forward) (m). & 2 & 193 & $0.80(0.48,1.11)$ & $0 \%$ \\
\hline \multicolumn{5}{|l|}{ Sensory measures } \\
\hline *9 Knee joint repositioning (degrees). & 2 & 58 & $-1.37(-2.29,-0.45)$ & $59 \%$ \\
\hline \multicolumn{5}{|l|}{ Cognitive measures } \\
\hline *10 Mini Mental State Exam. ++ & 4 & 229 & $0.37(-0.35,1.09)$ & $60 \%$ \\
\hline *11 Reaction time (s). Low value indicates better balance. & 3 & 198 & $-0.75(-1.45,-0.04)$ & $83 \%$ \\
\hline 11.1 Reaction time (s). Low value indicates better balance. & 2 & 132 & $-0.41(-0.84,0.01)$ & $33 \%$ \\
\hline
\end{tabular}

Note: Data is shown for 11 variables. For some variables there are two sets of data, the first set of data identified with * includes all available data, whereas the second set of data excludes studies at high risk of bias

Analyses with $<2$ studies providing data are not shown (maximal walking speed, functional reach (back, left, right), and range of motion are excluded) Higher value indicates better balance unless otherwise stated

++ Mean difference $(95 \% \mathrm{Cl})$ was calculated (MMSE and Handgrip test) and standardised mean $(95 \% \mathrm{Cl})$ calculated for all other measures.

results for one measure of flexibility with greater distances achieved for the functional reach test (forward) (SMD $0.80 \mathrm{~m})$.

Sensory measures Less active groups achieved statistically significant better results for one sensory measure of balance with better results on knee joint repositioning tests (SMD - 1.37).

There was no statistically significant difference between more active and less active groups for neuromuscular measures such as handgrip strength or cognitive measures such as MMSE scores or reaction time.

Secondary outcomes (direct measures of balance). Twelve variables were included in analyses (14 studies; $n=$ 801 participants) (Table 4: analyses highlighted*). However, for sensitivity analyses three studies were removed, due to high risk of bias ( $n=162$ participants) leaving ten variables (11 studies; $n=639$ participants) for analysis: significance levels decreased for static body stability eyes open and eyes closed (speed).

More active groups achieved statistically significant better results in three secondary outcome measures, with better tilt board results on directional control (SMD 1.02), and maximum excursion (SMD 1.09) as well as SOT visual ratios (SMD 0.13).

There was no statistically significant difference between more and less active groups for other measures of static or dynamic balance.

\section{Intervention studies}

Design, sample size, and location

Due to the inclusion criteria only four randomised controlled trials (RCTs) were included [49, 73-75]. Sample size ranged from 20 [74] to 60 [49] with an average of 38 participants, and only one study [49] justified sample size. 
Table 4 Secondary outcomes - more active versus less active groups (Direct measures of balance)

\begin{tabular}{|c|c|c|c|c|}
\hline Comparison or subgroup & $\begin{array}{l}\text { No. of } \\
\text { studies }\end{array}$ & N & Effect size & Heterogeneity \\
\hline *1 Somatosensory Organisation Test (Somatosensory. ratio).++ & 3 & 139 & $0.90(-0.58,2.38)$ & $81 \%$ \\
\hline 1.1 Somatosensory Organisation Test (Somatosensory. ratio). ++. & 2 & 63 & $0.16(003,0.29)$ & $0 \%$ \\
\hline *2 Somatosensory Organisation Test (Visual ratio). ++ & 3 & 139 & $-2.71(-3.99,-1.44)$ & $100 \%$ \\
\hline 2.1 Somatosensory Organisation Test (Visual ratio). ++ & 2 & 63 & $0.13(0.03,0.22)$ & $40 \%$ \\
\hline *3 Somatosensory Organisation Test (Vestibular ratio). ++ & 3 & 139 & $-0.02(-0.04,0.00)$ & $0 \%$ \\
\hline 3.1 Somatosensory Organisation Test (Vestibular ratio). ++ & 2 & 63 & $-0.02(-0.04,0.00)$ & $0 \%$ \\
\hline *4 Static total body stability eyes open (m). Low value indicates better balance. & 3 & 302 & $-0.37(-0.74,0.01)$ & $57 \%$ \\
\hline *5 Static total body stability eyes open $\left(\mathrm{cm}^{2}\right)$. Low value indicates better balance. & 4 & 231 & $-0.89(-2.11,0.33)$ & $93 \%$ \\
\hline 5.1 Static total body stability eyes open $\left(\mathrm{cm}^{2}\right)$. Low value indicates better balance. & 2 & 145 & $0.34(-0.25,0.94)$ & $66 \%$ \\
\hline *6 Static total body stability eyes open (velocity) (cm/s). Low value indicates better balance. & 3 & 161 & $-1.55(-3.35,0.25)$ & $95 \%$ \\
\hline 6.1 Static total body stability eyes open (velocity) $(\mathrm{cm} / \mathrm{s})$. Low value indicates better balance. & 2 & 135 & $0.07(-0.29,0.43)$ & $2 \%$ \\
\hline *7 Static total body stability eyes closed (velocity) (cm/s). Low value indicates better balance. & 3 & 161 & $-1.67(-3.50,0.16)$ & $95 \%$ \\
\hline 7.1 Static total body stability eyes closed (velocity) $(\mathrm{cm} / \mathrm{s})$. Low value indicates better balance. & 2 & 135 & $-3.05(-9.53,3.43)$ & $2 \%$ \\
\hline *8 Static ML stability body angle (degrees). Low value indicates better balance. & 2 & 96 & $-0.12(-0.52,0.28)$ & $0 \%$ \\
\hline *9 Static AP stability body angle (degrees). Low value indicates better balance. & 2 & 96 & $-0.11(-0.75,0.53)$ & $60 \%$ \\
\hline *10 Dynamic AP stability (forward) (angle ). Low value indicates better balance. & 2 & 72 & $0.01(-2.19,2.22)$ & $94 \%$ \\
\hline *11 Dynamic Loss of Stability (max excursion) (\%). Low value indicates better balance. & 2 & 68 & $1.09(0.57,1.60)$ & $0 \%$ \\
\hline *12 Dynamic Loss of stability (directional control) (\%). Low value indicates better balance. & 2 & 68 & $1.02(0.47,1.58)$ & $11 \%$ \\
\hline
\end{tabular}

Note: Data is shown for 12 variables. For some variables there are two sets of data, the first set of data identified with * includes all available data, whereas the second set of data excludes studies at high risk of bias

Higher value indicates better balance unless otherwise stated

++ Mean difference $(95 \% \mathrm{Cl})$ was calculated (SOT visual, vestibular and somatosensory ratios), and standardised mean (95\% Cl) calculated for all other measures

Of the four studies, one was US based [49] and the country for the remainder was not specified.

\section{Participants}

Participants across all studies were defined as healthy and resided in the community $(62 \%$ women; mean age $=$ 68.78 years), but there was a lack of more detailed demographic information. Average age of participants was 61-70 years in three studies [49, 73, 74], and 71 years or over in one study [75].

\section{Physical activity}

All studies included a less active group and a more active group, and all PA interventions were land based where two included '3D PA' ( $n=109$ participants) (Tai Chi) [49, 75 ], and two included 'General PA' ( $n=41$ participants) (walking) [73, 74]. Only one study used a validated PA assessment tool used (e.g. PASS) [49].

Intervention duration ranged from a minimum of three months $[73,74]$ to a maximum of six months $[49,75]$. All four provided results at baseline and post-trial commencement, at three months [73], at four months [74], at both two and six months [75], and at both three and six months [49].

\section{Balance}

All studies included a neuromuscular balance measure, but only one included a measure of the cognitive system (MMSE) [49], and none included any sensory system measures.

\section{Secondary outcome measures.}

One study used the SOT [75], and three used force plate platforms $[49,73,74]$.

\section{Quality}

Figure 2 presents a summary table of the risk of bias of included intervention studies, and shows a high risk of bias for all studies.

\section{Effects of more PA versus less $P A$}

Due to the limited number of studies and lack of common outcomes, a best evidence synthesis was explored [46].

Key findings relating to direct measures of balance Two studies reported direct measures [49, 73], but only one study provided these measures post-intervention measuring neuromuscular system health using gait speed only [73], and found that walking improved gait speed in more active groups. However, the study was at high risk of bias [29] and of low methodological quality (level 3) [46] and so provides limited evidence. 


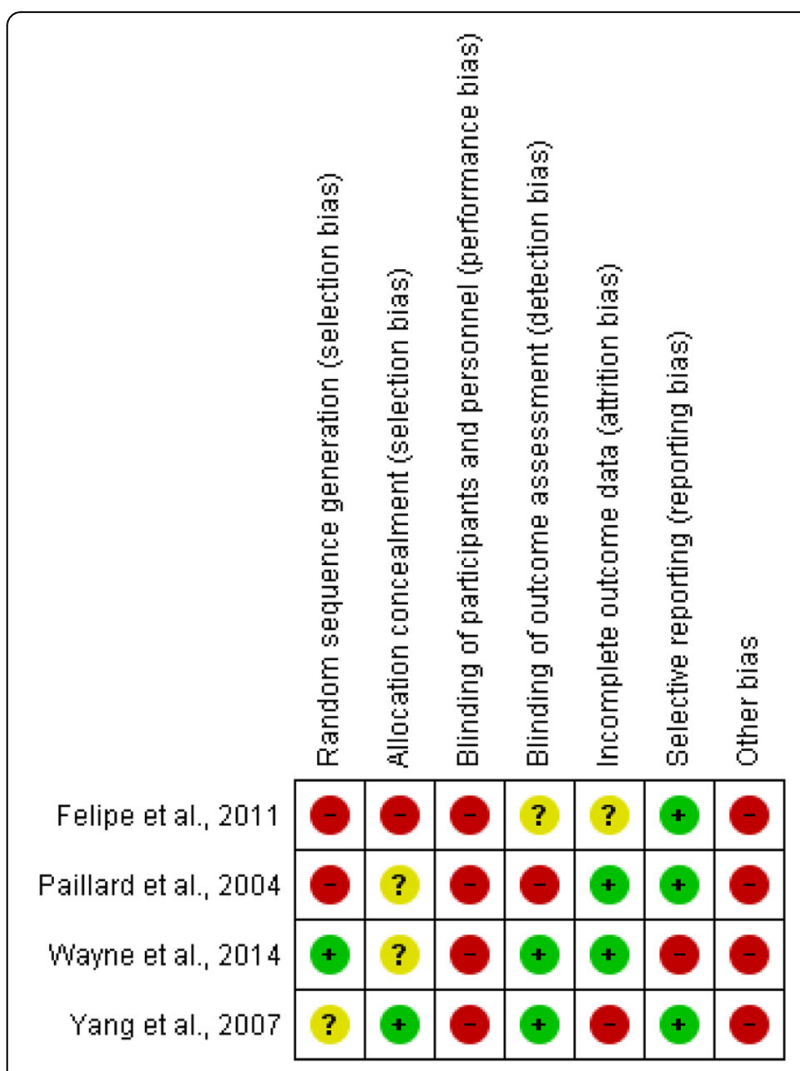

Fig. 2 A summary table of review authors' judgements for each risk of bias item for each study

Key findings relating to secondary measures of balance All four studies reported secondary measures of balance (e.g. SOT vestibular, BoS, and static and dynamic balance), and found that intervention groups had better balance scores. However, all studies were at high risk of bias [29] and of low methodological quality [46], and so evidence is again limited.

Key findings overall There is limited evidence that freeliving PA improves measures of balance in older healthy community-dwelling adults.

\section{Subgroup analyses}

The heterogeneity in the nature of the outcome data relating to age, type of PA and duration of effect meant that it was not possible to explore the effects of PA in relation to these variables.

\section{Discussion}

This review explored the role of free-living PA in relation to balance outcomes across multiple body systems, and summarises two types of evidence. The majority of evidence was from cross sectional studies (26 studies) of moderate methodological quality, and a much smaller number was from RCTs (four studies) of low methodological quality.
The evidence from cross sectional studies found that free-living PA [25-27] is beneficial for balance in older healthy community-dwelling adults (50 years and over), where more active groups experienced better performance on indirect measures of gait speed, strength, functionality and flexibility, and on direct measures of directional control, maximum excursion and SOT visual ratios. These findings extend the results from a previous longitudinal research exploring PA and physical performance by Cooper et al., that found that leisure-time PA carried out over the longer-term (17 years) can improve neuromuscular measures of strength in middle-aged adults (36-53 yrs) [76]. Additionally, evidence from the limited number of RCTs suggests that free-living PA improves measures of balance in the short-term (three-six months) in older healthy community-dwelling adults which extends the findings from previous research, that short-term (three-six months) exercise, a sub-category of PA, improves balance performance in older unhealthy adults $[8,13]$.

It is evident from this study that few RCTs have explored free-living PA and balance and that most evidence has been derived from observational studies, thus potentially providing insufficient clinical trial data on which to base clear conclusions. However, research suggests that the effects of free-living PA require a longer duration of study than that afforded by RCTs [77]. This review included observational studies that explored free-living PA of between one and 21 years' duration. In contrast, Howe et al.'s [13] systematic review of RCTs found no evidence that free-living PA such as walking or cycling, of up to 6 months' duration, improved measures of balance in older unhealthy adults. Thus, the benefits realised from free-living PA may be cumulative over time, and future research should consider the appropriateness of the study design involved in exploring associations between free-living PA and balance.

A strength of this review is that it considers balance as a multidimensional construct $[1,3]$ rather than a single system, and as a result, includes measures across neuromuscular, cognitive and sensory body systems, thus measures balance holistically. However, it is evident that whilst this review sought to include measures from multiple body systems, the majority of studies focused on neuromuscular measures (19 of 30 studies) and a smaller number included cognitive (ten) measures, and even less included sensory measures (three). Additionally, this study found no effect for cognitive measures relating to PA level, and this may be due to the inclusion of healthy older adults in the present study. As a result, future studies should seek to include measures across all the body systems required for balance, and include unhealthy adults.

Studies in the review reported validated measures for both balance and PA. Whilst most measures of PA were subjective, except for those in one study [47], the balance measures included were mainly objective, thus 
reducing any measurement bias due to self-reporting and or recall bias in the results [78].

There are some limitations to be taken into account when considering these findings. For example, sample size for both cross-sectional studies and RCTs were small ranging from 20 to 170 participants, and only justified by a power calculation in one study [49] which may give rise to Type II errors. Additionally, the observational studies included were cross sectional studies and therefore no causal relationship between free-living PA and balance can be determined. Also, participants were either volunteers or recruited using convenience sampling, therefore the generalisability of the findings is limited. In addition, whilst this review included multiple balance measures across different body systems, the number of different outcome measures $(n=40)$ restricted the ability to compare and pool results, and therefore future research in this emerging area should consider establishing a consensus of relevant balance measures across all body systems to aid analysis and fully understand the effects of free-living PA on balance.

In summary, this review suggests that free-living PA improves balance performance in older healthy adults both in the short-term and long-term using validated and objective measures across multiple body systems. Further research that incorporates higher quality studies is warranted, with the inclusion of longitudinal studies that provide large samples of participants using robust selection processes, and appropriate data over multiple time points. For example, studies such as NICOLA (Northern Ireland Cohort of Longitudinal Ageing) [79], TILDA (The Irish Longitudinal Study of Ageing) [32], and ELSA (English Longitudinal Study of Ageing) [31] include large samples of communitydwelling participants (50 years and over) $(8500,8504$ and 11, 391 respectively); provide data across multiple timepoints (between three and 11 years); adhere to the Gateway to Global Ageing Initiative [80] which improves the harmonisation of balance outcomes, therefore reducing the variability of outcomes and improving comparability of results; and include balance measures across multiple body systems that are objective and validated.

\section{Conclusion}

In conclusion, there is limited evidence from a small number of RCTs, and moderate quality of evidence from observational studies that suggests that free-living PA improves measures of balance in older communitydwelling healthy adults, particularly in respect of fall prevention. Future research should consider longitudinal studies of good methodological quality to improve the overall robustness of the findings.

\section{Additional files}

Additional file 1: Medline search example. (DOCX $12 \mathrm{~kb}$ )

Additional file 2: Table showing characteristics of excluded studies. (DOCX $27 \mathrm{~kb}$ )

\begin{abstract}
Abbreviations
ABC: Activities of Balance Confidence; AMED: Allied and Complementary Medicine Database; AP: Anterior Posterior; CDSR: Cochrane Database of Systematic Reviews; CENTRAL: Central Register of Controlled Trials; Cl: Confidence Interval; CINAHL: Cumulative Index to Nursing and Allied Health Literature; COP: Centre of Pressure; ELSA: English Longitudinal Study of Ageing; MEDLINE: Medical Literature Analysis and; ML: Medio Lateral; MLTPAQ: Minnesota Leisure Physical Activity Questionnaire; MMSE: Mini Mental State Exam; NOS: Newcastle Ottawa Scale; PA: Physical Activity (Free-living PA is activity for leisure, travel, occupational, or exercise); PASS: Physical Activity Status Score; PRISMA: Preferred Reporting Items for Systematic Reviews and Meta-Analyses; RAPA: Rapid Assessment of Physical Activity; RCT: Randomised Controlled Trials; SLS: Single Leg Stance;

SMD: Standardised Mean Difference; SOT: Sensory Organisation Test; TILDA: The Irish Longitudinal Study on Ageing; TUG: Timed up and Go test
\end{abstract}

\section{Acknowledgements}

SMD, BB, MC and MAT are co-funded by the UKCRC Centre of Excellence for Public Health (Northern Ireland), a UKCRC Public Health Research Centre of Excellence. Funding from the British Heart Foundation, Cancer Research UK, Economic and Social Research Council, Medical Research Council, Research and Development Office for the Northern Ireland Health and Social Services, and the Wellcome Trust, under the auspices of the UK Clinical Research Collaboration, is gratefully acknowledged.

\section{Funding}

This study was supported by a Ph.D. research grant from the Department of Employment and Learning, Northern Ireland.

\section{Availability of data and materials}

Data from the TILDA study are available upon request from the Irish Social Science Data Archive (ISSDA) at University College Dublin: http:// www.ucd.ie/issda/data/tilda/. and the Interuniversity Consortium for Political and Social Research (ICPSR) at the University of Michigan: http:// www.icpsr.umich.edu/icpsrweb/ICPSR/studies/34315.

\section{Consent of submission}

All authors have consented to the submission of this manuscript to the BMC Public Health Journal.

\section{Authors' contributions}

$\mathrm{SMD}, \mathrm{MC}, \mathrm{KC}, \mathrm{BB}$, and IIM were involved in the conception and design of the review. Screening of the articles was carried out by IIM, SMD, MC, and KC. Data extraction was carried out by IIM, MAT, and SMD. SMD, KC, and IIM carried out the risk of bias assessments. IIM conducted the meta-analyses and best evidence synthesis. IIM, SMD, and MAT contributed to the interpretation of the results. IIM wrote the review, and SMD, MC, KC MAT, and BB gave critical comments and advice that helped shape the review. All authors were fully involved in the study and preparation of the manuscript. All authors read and approved the final manuscript.

\section{Ethics approval and consent to participate} Not applicable.

\section{Consent for publication}

Not applicable.

\section{Competing interests}

The authors declare that they have no competing interests.

\section{Publisher's Note}

Springer Nature remains neutral with regard to jurisdictional claims in published maps and institutional affiliations. 


\section{Author details}

'UKCRC Centre of Excellence for Public Health (NI), Ulster University, Jordanstown, County Antrim, Northern Ireland. ${ }^{2}$ Institute of Nursing and Health Research, Ulster University, Jordanstown, County Antrim, Northern Ireland. ${ }^{3}$ School of Physiotherapy, University of Otago, Dunedin, New Zealand. ${ }^{4}$ UKCRC Centre of Excellence for Public Health (NI); Centre for Public Health, School of Medicine, Dentistry and Biomedical Sciences, Queen's University Belfast, University Road, Belfast BT7 1NN, Northern Ireland. ${ }^{5}$ UKCRC Centre of Excellence for Public Health (NI); Centre for Public Health, School of Medicine, Dentistry and Biomedical Sciences, Queen's University Belfast, Belfast, Northern Ireland. ${ }^{6}$ Institute of Nursing and Health Research, Ulster University, Jordanstown, County Antrim, Northern Ireland. ${ }^{7}$ UKCRC Centre of Excellence for Public Health (NI); Psychology Department, Ulster University, Jordanstown, County Antrim, Northern Ireland.

Received: 5 January 2018 Accepted: 6 March 2018

Published online: 02 April 2018

\section{References}

1. Horak FB. Postural orientation and equilibrium: what do we need to know about neural control of balance to prevent falls? Age Ageing. 2006:35-52. https://doi.org/10.1093/ageing/afl077.

2. Shumway-Cook A, Woollcott MH. Motor control: translating research into clinical practice. 3rd ed. Philadelphia: Lippincott Williams \& Wilkins; 2007

3. Thomas JC, Odonkor C, Griffith L, Holt N, Percac-Lima S, Leveille S, Ni P, Latham NK, Jette AM, Bean JF. Reconceptualizing balance: attributes associated with balance performance. Exp Gerontol. 2014;57:218-23.

4. Bandeen-Roche K, Seplaki CL, Huang J, Buta B, Kalyani RR, Varadhan R, Xue Q, Walston JD, Kasper JD. Frailty in older adults: a nationally representative profile in the United States. J Gerontol A Biol Sci. 2015;70(11):1427-34.

5. Brigola AG, Rossetti ES, Rodrigues dos Santos B, Neri AL, Zazzetta MS, Inouye K, Lost Pavarini SC. Relationship between cognition and frailty in elderly: a systematic review. Dement Neuropsychol. 2015;9(2):110-9.

6. Bucknix F, Rolland Y, Reginster JY, Ricour C, Petermans J, Bruyere O. Burden of frailty in the elderly population: perspectives for a public health challenge. Archives of Public Health. 2015;73:19. https://doi.org/10.1186/s13690-015-0068-X.

7. Chen X, Mao G, Leng SX. Frailty syndrome: an overview. Clinical Interventions in Ageing. 2014;9:433-41.

8. Gillespie LD, Robertson MC, Gillespie WJ, Sherrington C, Gates S, Clemson LM, Lamb SE. Interventions for preventing falls in older people living in the community. Cochrane Database Syst Rev. 2012; Art. No.: CD007146. https:// doi.org/10.1002/14651858.CD007146.pub3

9. Karlsson MK, Magnusson H, Schewelov T, Rosengren BE. Prevention of falls in the elderly-a review. Osteoporos Int. 2013;24:747-62. https://doi. org/10.1007/s00198-012-2256-7.

10. Worldwide Health Organisation (WHO). WHO global report on falls prevention in older age. Downloaded from: http://www.who.int/ageing/ publications/Falls_prevention7March.pdf. 2007. Accessed 27 Sept 2015.

11. Chodzko-Zajko WJ, Proctor DN, Fiatarone Singh MA, Minson CT, Nigg CR, Salem GJ, Skinner JS. (2009). American college of sports medicine stand on exercise and physical activity for older adults. Med Sci Sports Exerc. 2009; 41(7):1510-30.

12. Cooper R, Kuh D, Hardy R. Mortality review group, FALCon \& HALCyon study teams. Objectively measured physical capability levels and mortality: systematic review and meta-analysis. BMJ. 2010;341:c4467. https://doi.org/10.1136/bmj. c4467.

13. Howe TE, Rochester L, Neil F, Skelton DA, Ballinger C. Exercise for improving balance in older people. Cochrane Database Syst Rev. 2011;(11) Art. No. CD004963. https://doi.org/10.1002/14651858.CD004963.pub.

14. Stubbs B, Brefka S, Denkinger MD. What works to prevent falls in community dwelling older adults? Umbrella review of meta-analyses of randomized controlled trials. Phys Ther. 2015;95(8) Downloaded from: http://ptjournal.apta.org/content/early/2015/05/14/ptj.20140461

15. Kannus $P$, Palvanen $M$, Niemi $S$, Parkkari J. Alarming rise in the number and incidence of fall-induced cervical spine injuries among older adults. J Gerontol A Biol Sci Med Sci. 2007;62A(2):180-3.

16. Worldwide Health Organisation (WHO). World report on ageing and health. 2015: http://apps.who.int/iris/bitstream/10665/186463/1/9789240694811eng.pdf?ua=. Accessed 2 Nov 2015.

17. Cadore EL, Rodriguez-Manas L, Sinclair A, Izquierdo M. Effects of different exercise interventions on risk of falls, gait ability, and balance in physically frail older adults: a systematic review. Rejuvenation Res. 2013;16(2):105-14. https://doi.org/10.1089/rej.2012.1397.

18. Chief medical officer (CMO). Start active, stay active. A report on physical activity for health from the four home countries' chief medical officers. 2011; Downloaded from https://www.gov.uk/government/publications/startactive-stay-active-a-report-on-physical-activity-from-the-four-homecountries-chief-medical-officers. Accessed 12 Oct 2015.

19. Sherrington C, Tiedemann A, Fairhall N, et al. Exercise to prevent falls in older adults: an updated meta-analysis and best practice recommendations. N S W Public health bull. 2011;22:78-83.

20. Worldwide Health Organisation. Global recommendations on physical activity for health. 2010; http://www.who.int/dietphysicalactivity/factsheet_ recommendations/en/. Downloaded 20 June 2017.

21. Hallal P, Anderson LB, Bull F, Gothold R, Haskell W, Ekelund U. Global physical activity levels: surveillance progress, pitfalls, and prospect. Lancet. 2012;386:247-57.

22. Schutzer KA, Graves S. Barriers and motivations to exercise in older adults. Prev Med. 2004:39:1056-61.

23. Baert V, Gorusa E, Metsa T, Geertsa C, Bautmansa I. Motivators and barriers for physical activity in the oldest old: a systematic review. Ageing Res Rev. 2011;10:464-74

24. Chao D, Foy CG, Farmer D. Exercise adherence among older adults: challenges and strategies. Control Clin Trials. 2000;21:212S-7S.

25. Howley TE. Types of activity: resistance, aerobic and leisure versus occupational physical activity. Med. Sci. Sports Exerc. 2001;33(6):S364-9.

26. Worldwide Health Organization (WHO). Global recommendations on physical activity for health. 65 years and above. Available from: http://who. int/dietphysicalactivity/physical-activity-recommendations-65years.pdf?ua=1. 2011; Accessed 2 May 2017.

27. Worldwide Health Organisation (WHO). Global physical activity questionnaire (GPAQ) analysis guide: http://www.who.int/chp/steps/ resources/GPAQ_Analysis_Guide.pdf?ua=1. 2013; Accessed 6 Apr 2016.

28. Liberati A, Altman DG, Tetzlaff J, Mulrow C, Gotzsche PC, loannidis JP, Clarke M, Devereaux PJ, Kleijnen J, Moher D. The PRISMA statement for reporting systematic reviews and meta-analysis of studies that evaluate healthcare interventions: explanations and elaboration. BMJ. 2009;339:b2700. PMID: 19622552. https://doi.org/10.1136/bmj.b2700.

29. Higgins JPT, Altman DG, Gøtzsche PC, Jüni P, Moher D, Oxman AD, Savović J, Schulz KF, Weeks L. Sterne JAC \& Cochrane bias methods group. The Cochrane Collaboration's tool for assessing risk of bias in randomised trials. BMJ. 2011;343:d5928. https://doi.org/10.1136/bmj.d5928

30. National Institute for Health Research Library: www.nihr.ac.uk. Accessed Apr 2017.

31. English Longitudinal Study of Ageing: http://www.elsa-project.ac.uk.

32. The Irish Longitudinal Study of Ageing: http://tilda.tcd.ie/.

33. Winter DA. ABC: anatomy, biomechanics and control of balance during standing and walking. Waterloo: Waterloo Biomechanics; 1995.

34. Graham JE, Ostir GV, Fisher SR, Ottenbacher KJ. Assessing walking speed in clinical research: a systematic review. J Eval Clin Pract. 2008:1356-294.

35. Rose DJ. Physical activity instruction of older adults. In: Jones CJ, Rose DJ, editors. Champaign: Human Kinetics; 2005. p. 211-27.

36. Refworks (2.0). ProQuest LLC, Mitchigan, US. 2018.

37. National Institute for Health and Care Excellence (NICE). Process and methods guides: developing NICE guidelines: the manual appendices A-I. Downloaded from: https://www.nice.org.uk/media/default/About/what-wedo/NICE-guidance/NICE-guidelines/developing-NICE-guidelines-the-manual. pdf. 2015; Accessed 21 Apr 2016.

38. Hartling L, Milnea A, Hamma MP, Vandermeera B, Ansari M, Tsertsvadzec A, Drydena DM. Testing the Newcastle Ottawa scale showed low reliability between individual reviewers. J Clin Epidemiol. 2013;66:982-93.

39. Herzog R, Álvarez-Pasquin MJ, Díaz C, Del Barrio JL, Estrada JM, Gil A. Are healthcare workers' intentions to vaccinate related to their knowledge, beliefs and attitudes? A systematic review. BMC Public Health. 2013;13:1-17.

40. Wells GA, Shea B, O'Connell D, Robertson J, Peterson J, Welch V, Logos M Tugwell $P$. The Newcastle-Ottawa scale (NOS) for assessing the quality of nonrandomised studies in meta-analyses, Ottawa Hospital Research Institute, Ottawa, Canada. 2010; Downloaded from: http://www.evidencebasedpublichealth.de/download/ Newcastle_Ottowa_Scale_Pope_Bruce.pdf, 2017.

41. Borenstein $M$, Hedges LV, Higgins JPT, Rothstein HR. Introduction to metaanalysis: Wiley; 2009. ISBN: 978-0-470-05724-7 chaper40

42. Lamb SE, Jorstad-Stein EC, Hauer K, Becker C. Development of a common outcome data set for fall injury prevention trials: the prevention of falls network Europe consensus. JAGS. 2005;53:1618-22. 
43. Review Manager (RevMan). 5.1. Copenhagen: the Nordic Cochrane Centre, the Cochrane collaboration. 2011.

44. O'Connor SR, Tully MA, Ryan B, Bleakley CM, Baxter GD, Bradley JM, McDonough SM. Walking exercise for chronic musculoskeletal pain: systematic review and meta-analysis. Arch Phys Med Rehabil. 2015;96:724-34.

45. Ainsworth BE, Haskell WL, Whitt MC, Irwin ML, Swartz AM, Strath SJ, O'Brien WL, Bassett DR, Schmitz KA, Emplalncourt PO, Jacobs DR, Leon AS. Compendium of physical activities: an update of activity codes and MET intensities. Med. Sci. Sports Exerc. 2000;32(9 Suppl): S498-516.

46. Van Tulder MW, Esmail R, Bombardier C, Koes BW. Back schools for nonspecific low back pain. Cochrane Database Syst Rev. 2000;2:CD000261.

47. Aoyagi Y, Park H, Watanabe E, Park S, Shephard RJ. Habitual physical activity and physical fitness in older Japanese adults: the Nakanojo study. Gerontology. 2009;55(5):523-31.

48. Gao KL, Hui-Chan CW, Tsang WW. Golfers have better balance control and confidence than healthy controls. Eur J Appl Physiol. 2011;111(11):2805-12.

49. Wayne PM, Gow BJ, Costa MD, Peng CK, Lipsitz LA, Hausdorff JM, Davis RB, Walsh JN, Lough M, Novak V, Yeh GY, Ahn AC, Macklin EA, Manor B. Complexity-based measures inform effects of tai chi training on standing postural control: cross-sectional and randomised trial studies. PLoS One. 2014;9(12):e114731. https://doi.org/10.1371/journal.pone.0114731

50. Brooke-Wavell K, Cooling VC. Fall risk factors in older female lawn bowls players and controls. J Aging Phys Act. 2009;17(1):123-30.

51. Buatois S, Gauchard GC, Aubry C, Benetos A, Perrin P. Current physical activity improves balance control during sensory conflicting conditions in older adults. Int J Sports Med. 2007;28(1):53-8.

52. Fong S, Ng GY. The effects on sensorimotor performance and balance with tai chi training. Arch Phys Med Rehabil. 2006;87(1):82-7.

53. Fong SS, Ng SS, Liu KP, Pang MY, Lee HW, Chung JW, Lam PL, Guo X, Manzaneque JM. Musculoskeletal strength, balance performance, and selfefficacy in elderly Ving Tsun Chinese martial art practitioners: implications for fall prevention. Evid Based Complement Alternat Med. 2014; Article ID 402314: 6 pages: http://dx.doi.org/10.1155/2014/402314

54. Gauchard GC, Jeandel C, Tessier A, Perrin PP. Beneficial effect of proprioceptive physical activities on balance control in elderly human subjects. Neurosci Lett. 1999;273(2):81-4.

55. Gauchard GC, Jeandel C, Perrin PP. Physical and sporting activities improve vestibular afferent usage and balance in elderly human subjects. Gerontology. 2001;47(5):263-70

56. Gauchard GC, Gangloff P, Jeandel C, Perrin PP. Influence of regular proprioceptive and bioenergetic physical activities on balance control in elderly women. J Gerontol A-Biol Sci Med Sci. 2003;58(9):M846-50.

57. Hakim RM, Kotroba E, Cours J, Teel S, Leininger PM. A cross-sectional study of balance-related measures with older adults who participated in tai chi, yoga, or no exercise. Phys Occupational Ther in Geriatrics. 2010;28(1):63-74.

58. Rahal MA, Alonso AC, Andrusaitis FR, Rodrigues TS, Speciali DS, Greve JMDA, Leme LEG. Analysis of static and dynamic balance in healthy elderly practitioners of tai chi Chuan versus ballroom dancing. Clinics (Sao Paulol). 2015;70(3):157-61.

59. Tsang WWN, Hui-Chan CWY. Effects of exercise on joint sense and balance in elderly men: tai chi versus golf. Med Sci Sports Exerc. 2004;36(4):658-67.

60. Tsang WWN, Hui-Chan CWY. Comparison of muscle torque, balance, and confidence in older tai chi and healthy adults. Med Sci Sports Exerc. 2005;37(2):280-9.

61. Tsang WWN, Hui-Chan CWY. Standing balance after vestibular stimulation in tai chi-practicing and nonpracticing healthy older adults. Arch Phys Med Rehabil. 2006:87(4):546-53.

62. Tsang WWN, Hui-Chan CWY. Static and dynamic control in older golfers. J Aging Phys Act. 2010;18:1-13.

63. Zhang C, Mao D, Riskowski JL, Song Q. Strategies of stepping over obstacles: the effects of long-term exercise in older adults. Gait Posture. 2011;34(2):191-6.

64. Gyllensten AL, Hui-Chan CWY, Tsang WWN. Stability limits, single-leg jump and body awareness in older tai chi practitioners. Arch Phys Med Rehabil. 2010;91(2):215-20.

65. Lu X, Siu KC, Fu SN, Hui-Chan CW, Tsang WWW. Tai chi practitioners have better postural control and selective attention in stepping down with and without a concurrent auditory response task. Eur J Appl Physiol. 2013;113(8):1939-45.
66. Tsang WWW, Wong VS, Fu SN, CWY H-C, Chi T. Improves standing balance control under reduced or conflicting sensory conditions. Arch Phys Med Rehabil. 2004;85(1):129-37.

67. Wong AM, Lin Y, Chou S, Tang F, Wong P. Coordination exercise and postural stability in elderly people: effect of tai chi Chuan. Arch Phys Med Rehabil. 2001;82(5):608-12

68. Wong AM, Chou S, Huang S, Lan C, Chen H, Hong W, Chen CPC, Pei Y. Does different exercise have the same effect of health promotion for the elderly? Comparison of training-specific effect of tai chi and swimming on motor control. Arch Gerontol Geriatr. 2011;53(2):e133-7.

69. Dewhurst S, Nelson N, Dougall PK, Bampouras TM. Scottish country dance: benefits to functional ability in older women. J Aging Phys Act. 2014;22(1):146-53.

70. Hakim RM, DiCicco J, Burke J, Hoy T, Roberts E. Differences in balance related measures among older adults participating in tai chi, structured exercise, or no exercise. J Geriatr Phys Ther. 2004;27(1):11-5.

71. Guadagnin EC, da Rocha ES, Mota CB, Carpes FP. Effects of regular exercise and dual tasking on spatial and temporal parameters of obstacle negotiation in elderly women. Gait Posture. 2015;42(3):251-6.

72. Perrin PP, Gauchard GC, Perrot C, Jeandel C. Effects of physical and sporting activities on balance control in elderly people. Br J Sports Med. 1999;33(2):121-6.

73. Paillard T, Lafont C, Costes-Salon MC, Riviere D, Dupui P. Effects of brisk walking on static and dynamic balance, locomotion, body composition, and aerobic capacity in ageing healthy active men. Int J Sports Med. 2004;25(7):539-46.

74. Santos Mendes FA, Caromano FA, Ide MR, Schujmann DS, Almeida MHM, Carvalho EV. General versus walking exercises on the static and dynamic balance of healthy elderly persons. Ter Man. 2011;9(46):167-74.

75. Yang Y, Verkuilen JV, Rosengren KS, Grubisich SA, Reed MR, Hsiao-Wecksler ET. Effect of combined Taiji and qigong training on balance mechanisms: a randomized controlled trial of older adults. Med Sci Monit. 2007;13(8):R339-48.

76. Cooper R, Mishra GD, Kuh D. Physical activity across adulthood and physical performance in midlife. Findings from a British birth cohort. Am J Prev Med. 2011:41(4):376-84

77. Morris JN, Hardman AE. Walking to health. Sports Med. 1997;23(5):306-32.

78. Hillsdon MM, Brunner EJ, Guralnik JM, Marmot MG. Prospective study of physical activity and physical function in early old age. Am J Prev Med. 2005;28:245-50.

79. Northern Irish Cohort of Longitudinal Ageing Study: https://www.mrc.ac/ research/facilities-and-resources-for-researchers/cohort-directory/northernireland-cohort-longitudinal-study-of-ageing-nicola/.

80. Gateway to Global Ageing Initiative: https://g2aging.org/. Accessed Aug 2016.

\section{Submit your next manuscript to BioMed Central and we will help you at every step:}

- We accept pre-submission inquiries

- Our selector tool helps you to find the most relevant journal

- We provide round the clock customer support

- Convenient online submission

- Thorough peer review

- Inclusion in PubMed and all major indexing services

- Maximum visibility for your research

Submit your manuscript at www.biomedcentral.com/submit 